\title{
New Design of Dams on Zambezi River
}

\author{
Aijing Liư ${ }^{1, a}$ \\ ${ }^{1}$ North China Electric Power University (Baoding), Hebei 071000, China \\ a1228262272@qq.com
}

Keywords: the Kariba Dam, Safe Operation Model, Multi-Objective Programming.

\begin{abstract}
A lot of attention has recently been paid to the crisis of the Kariba Dam on the Zambezi River. The dam is in urgent need of maintenance. In order to solve this problem, a series of models are established, and the construction scheme of the dams is studied in detail. At first we establish Safe Operation Model. In this model, we study the relationship between overflow risk rate and dam numbers to determine the approximate range of the quantity. We then analyze the cost and the benefits of the project. Finally, the number of dams is determined by the cost and the benefits. The optimal number of dams that we have calculated is 16 . At last, we analyze the results of each of these models, performing sensitivity analysis on the input parameters and demonstrating their flexibility. Then we analyze the strength and weakness of the model.
\end{abstract}

\section{Introduction}

The Kariba Dam on the Zambezi River has recently attracted widespread worldwide attention. As one of Africa's larger dams, its construction is controversial. Today, the Caliba dams have been disrepaired with spillways, and associated infrastructure, and the South African Institute for Risk Management's 2015 report includes a warning that the dam is in urgent need of maintenance. If a new system of dams is to be built, we must ensure that it has the same or better overall water management capabilities than the Kariba Dam, while providing existing dams with the same or greater levels of protection and water management options. So a more detailed analysis is needed of the program to dismantle the Kariba dam and replace it with a series of ten to twenty smaller dams.

In our basic model, we assume some reasonable conditions to simplify the problem. The problem is solved by analyzing many aspects such as economy, security, rationality and so on.

At first we establish Safe Operation Model. In this model, we study the relationship between overflow risk rate and dam numbers to determine the approximate range of dams. Finally, the number of dams is determined by the cost problem.

\section{Assumptions and Justification}

To simplify the problem and make it convenient for us to simulate real conditions, we make the following basic assumptions, each of which is properly justified.

- Dam operating conditions will not be affected by other factors. The operational status of the dam is only affected by the natural conditions and the administrator's control. This is to take into account the relationship between the operation of the dam and the state of nature and management.

- It is assumed that there is no additional loss of water from upstream to downstream. We ignore the evaporation of water, the amount of water consumed by humans or animals and so on. Because the loss of these water effects on the model is small

- The impacts of accidents on dams construction costs and economic benefits can be ignored. Our model does not consider accidents such as earthquakes, landslides or wars.

- The information and data that we receive from the Internet, books, and literature are accurate and reliable. Some of the data and formulas in this article are from the Web, literature and books, and we believe they are scientific. 


\section{Notations}

Table 1 The variation of parameters

\begin{tabular}{cl}
\hline Symbols & Definition \\
\hline $\mathrm{N}$ & Total quantity of required smaller dams \\
$V_{i}$ & Number of dams \\
$M_{i}$ & Maximum safety discharge of the ith dam \\
$W_{i}$ & Inflow of the ith dam \\
$Q_{i}$ & Not overflow probability of the ith dam \\
$P_{i}$ & Overflow risk rate of the ith dam \\
$\lambda_{i}$ & Negative exponential distribution law of the ith dam
\end{tabular}

Where we define the main parameters while specific value of those parameters will be given later.

\section{Safe Operation Model}

\section{Model Establishment.}

The contact medium between Cascade Dams is flood (runoff). Water storage capacity is the main factor to determine reservoir safety. Therefore, to fully consider the impact of upstream reservoirs on downstream reservoirs, it is necessary to start from the analysis of the flood volume relationship between cascade reservoirs (Xi iuyi, 2006).

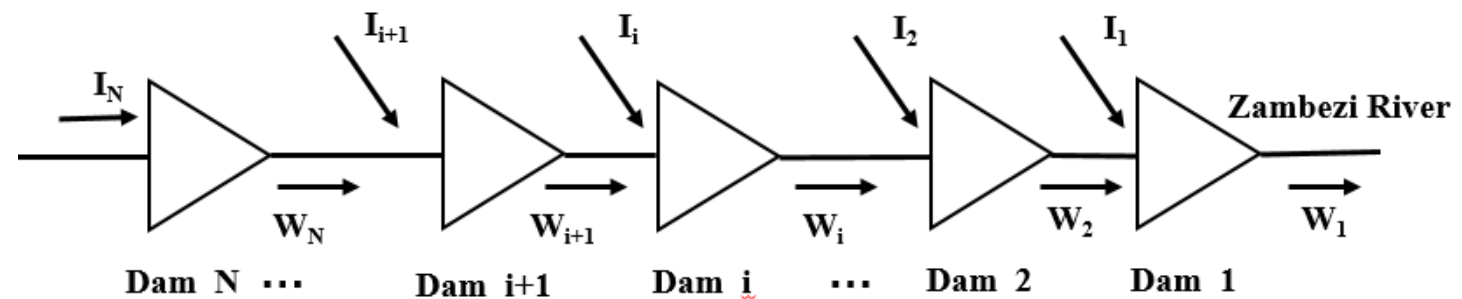

Fig. 1 The system of $\mathrm{N}$ reservoirs in series

Assume that $\mathrm{N}$ dams are built on the Zambezi River, as shown in Figure 1 . The most downstream dam is numbered 1, the upper level is numbered 2, and it is numbered up to $\mathrm{N}$ in order. The storage capacity for flood control $V_{i}$ and the maximum safety discharge $M_{i \mathrm{i}}$ of the dams can be obtained by the dam characteristics and downstream constraints.

Under the premise of the upstream dam security, the flood control safety of the downstream reservoir depends on the inflow of dam $W_{i}$, its flood control capacity and other factors. The flood volume between the dams are not related to each other. The inflow of the dam, numbered $\mathrm{i}$, is a combination of the water flow discharged from the upstream dam and the flood within the interval, and obeys the negative exponential distribution rate $\lambda$.

According to the probability density function of the flood analysis, we obtain the following equation.

$$
\begin{gathered}
Y_{\mathrm{i}}=V_{\mathrm{i}}+M_{\mathrm{i}}-M_{\mathrm{i}+1} \\
Q_{\mathrm{i}}=Q_{\mathrm{i}+1}\left[1-e^{\frac{1}{\mu_{\mathrm{i}}} Y_{i}}\right]+P_{\mathrm{i}+1}\left[1-e^{\frac{1}{\mu_{\mathrm{i}}+\mu_{\mathrm{i}+1}} Y_{i}}\right] \\
P_{\mathrm{i}} \lambda_{\mathrm{i}}=Q_{\mathrm{i}+1} \frac{1}{\mu_{i}} e^{-\frac{1}{\mu_{i}} Y_{i}}+P_{\mathrm{i}+1} \frac{1}{\mu_{\mathrm{i}}+\mu_{i+1}} e^{-\frac{1}{\mu_{\mathrm{i}}+\mu_{\mathrm{i}+1}} Y_{i}}
\end{gathered}
$$




$$
\begin{gathered}
P_{\mathrm{i}}+Q_{\mathrm{i}}=1 \\
\mu_{N}=\frac{1}{\lambda_{\mathrm{N}}} \\
P_{W}=e^{-\mathrm{iW}\left(v_{N}+M_{N} \mathrm{~J}\right.}
\end{gathered}
$$

where $Q_{\mathrm{i}}$ is not overflow probability of the ith dam,

$P_{\mathrm{i}}$ is overflow risk rate of the ith dam,

$\lambda_{i}$ is negative exponential distribution law of the ith dam.

According to the above formula, it is possible to calculate the overflow risk rate of each dam from the dam $\mathrm{N}$ to the downstream. Ultimately, we can obtain the relationship between the overflow risk rate and the number of dams.

\section{Results.}

Through the MATLAB programming solution, we can get the overflow probabi-lity of the dams. The results are shown in Table 2 .

Table 2 The overflow risk rate of the dams

\begin{tabular}{cccccc}
\hline & $\mathrm{N}=14$ & $\mathrm{~N}=15$ & $\mathrm{~N}=16$ & $\mathrm{~N}=17$ & $\mathrm{~N}=18$ \\
\hline 1 & 0.7120 & 0.7020 & 0.6765 & 0.6970 & 0.7140 \\
2 & 0.7200 & 0.6910 & 0.6720 & 0.6820 & 0.6840 \\
3 & 0.6500 & 0.6950 & 0.6658 & 0.6720 & 0.6640 \\
4 & 0.6320 & 0.6880 & 0.6520 & 0.6650 & 0.5600 \\
5 & 0.5500 & 0.4500 & 0.6200 & 0.5560 & 0.6000 \\
6 & 0.5200 & 0.5500 & 0.5920 & 0.5460 & 0.5870 \\
7 & 0.4600 & 0.5200 & 0.5670 & 0.5000 & 0.5500 \\
8 & 0.3710 & 0.4520 & 0.5560 & 0.4650 & 0.5000 \\
9 & 0.4220 & 0.4200 & 0.5200 & 0.4450 & 0.5200 \\
10 & 0.2920 & 0.3950 & 0.5100 & 0.4260 & 0.4860 \\
11 & 0.3450 & 0.3850 & 0.4800 & 0.4030 & 0.4500 \\
12 & 0.2930 & 0.3420 & 0.3596 & 0.3820 & 0.4600 \\
13 & 0.2450 & 0.3100 & 0.4230 & 0.3560 & 0.4000 \\
14 & 0.2230 & 0.2600 & 0.3352 & 0.3470 & 0.2560 \\
15 & - & 0.2230 & 0.2960 & 0.3170 & 0.3750 \\
16 & - & - & 0.2230 & 0.2460 & 0.2900 \\
17 & - & - & - & 0.2230 & 0.2450 \\
18 & - & - & - & - & 0.2230
\end{tabular}

We can get the relationship between the overflow risk rate of the dams and the total dam quantity, as shown in Fig.2.

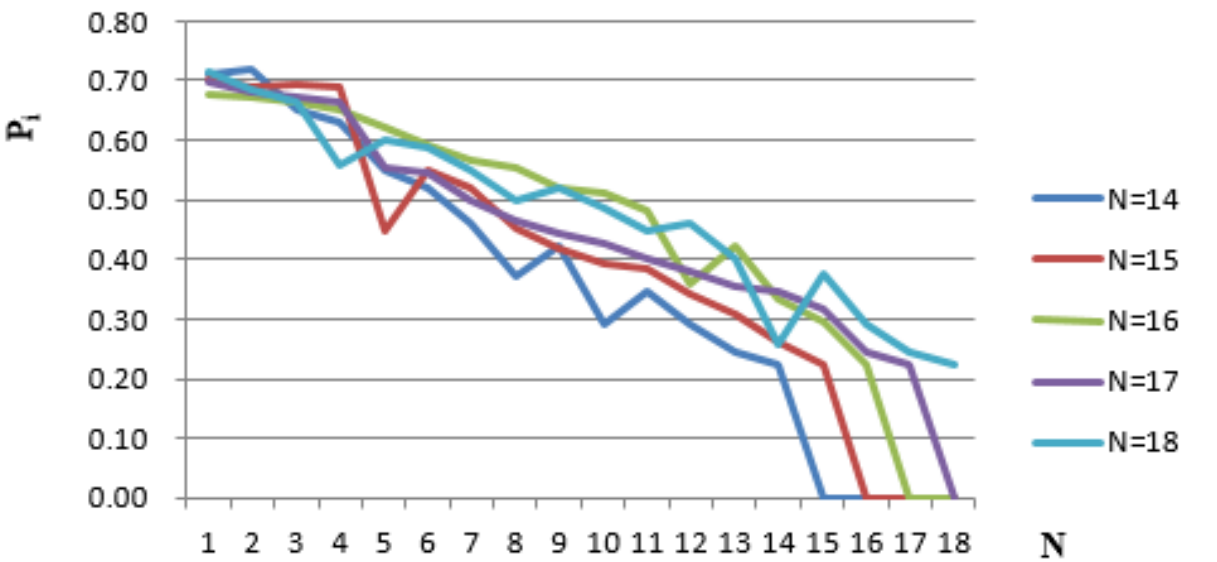

Fig. 2 the overflow risk rate of the dams 
According to the "bucket effect", in order to make these dams to be the safest, its maximum overflow risk rate should be the lowest. As can be seen from the figure 3 , the optimum total number of dams should be 16 .

\section{Summary}

We are required to establish a model to determine the relationship between the parameters of dams and the performance of these dams. Then we are expected to propose the best strategy for the Zambezi River Authority (ZRA) to ensure that it has the same or better overall water management capabilities than the Kariba Dam, while providing existing dams with the same or greater levels of protection and water management options. In addition, we need a model to study the relationship between the total flood discharge and the flood discharge ofeach dam to consider the adjustment scheme for the dams in different seasons.

We establish Safe Operation Model. In this model, we study the relationship between overflow risk rate and dam numbers to determine the approximate range of the quantity. We then analyze the cost and the benefits of the project. Finally, the number of dams is determined by the cost and the benefits. The optimal number of dams that we have calculated is 16.

\section{Strength and Weakness}

\section{Strength.}

- The goal optimization model has a better effect on the goal. Targeting water saving and safety conforms to the real circumstances.

- Using the analog method to select the sites, which solves the problem of lack of data due to lack of influence.

\section{Weakness.}

- The goal of the model is a single one, which fails to take security and cost issues into account.

- The randomness of the evaluation process, the subjective uncertainty of the evaluator and the fuzziness of cognition.

- Did not consider the impact of human factors on the dam, which may have a significant impact.

\section{References}

[1]. A. M. Geoffrion, J. S. Dyer, A. Feinberg. An Interactive Approach for Multi-Criterion Optimization, with an Application to the Operation of an Academic Department [J]. Management Science, 1972:357 - 368.

[2]. B. Navneet, K. Rai. Strategic Decision Making: Applying the Analytic Hierarchy Process [M]. London: Springer-Verlag, 2004.

[3]. F. Darboux, C. Gascue Odoux, P. Davy. Effects of surface water storage by soil roughness on overland-flow generation [J]. Earth Surface Processes and Landforms, 2002, 27(3): 223 - 233.

[4]. Fan Hui. The Construction of a Watershed Management Mechanism Based on Multicriteria Analysis[J]. Journal of Anhui Agricultural Sciences,2012,(10):6123-6124, 6127.

[5]. P. B. Bedient, W. C. Huber, B. E. Vieux. Hydrology and floodplain analysis [M]. fourth edition. New York: Prentice Hall, 2008.

[6]. Xi Qiuyi. The study of flood safety risk rate model and flood control standard of reservoirs (group)[D]. Xi'an: Xi'an University of Technology. 2006: 87-89.

[7]. Y. Martin, C. Valeo, M. Tait. Centimetre-scale digital representation of terrain and impacts on depression storage and runoff [J]. Catena, 2008, 75(2): 223 - 233.

[8]. Z. P. Chen. Introduction to waterpower project [M]. Beijing: China WaterPower Press, 2006. 